\title{
The Role of TGF Beta 1 and PDGF BB in Wound Healing of the Palate
}

\author{
Olivia Avriyanti Hanafiah \\ Department of Oral and Maxillofacial Surgery \\ Faculty of Dentistry, Universitas Sumatera Utara \\ Medan, Indonesia \\ olivia_avriyanti@yahoo.com \\ Devina Angga \\ Department of Oral and Maxillofacial Surgery \\ Faculty of Dentistry, Universitas Sumatera Utara \\ Medan, Indonesia \\ Syafrudin Ilyas \\ Department of Biology \\ Faculty of Mathematics and Sains, \\ Universitas Sumatera Utara \\ Medan, Indonesia
}

\author{
Reevanash Poravi \\ Department of Oral and Maxillofacial Surgery \\ Faculty of Dentistry, Universitas Sumatera Utara \\ Medan, Indonesia
}

Trimurni Abidin

Department of Oral and Maxillofacial Surgery

Faculty of Dentistry, Universitas Sumatera Utara

Medan, Indonesia

Marline Nainggolan

Department of Pharmacology and Pharmaceutical Biology

Faculty of Dentistry, Universitas Sumatera Utara

Medan, Indonesia

\author{
Endang Syamsudin \\ Department of Oral and Maxillofacial Surgery \\ Faculty of Dentistry, Universitas Padjajaran \\ Bandung, Indonesia
}

\begin{abstract}
Oral wound healing is a process that consists of three highly integrated and overlapping phases inflammation, proliferation and tissue remodelling. These phases involve the interaction between many cells and growth factors that work together from the beginning of an injury to complete tissue formation either through regeneration of tissue or by scar formation. At the point of injury, circulating platelets are capable of secreting growth factors needed during the wound healing phases. Growth factors such as transforming growth factor beta1(TGF-B1) and platelet-derived growth factor-BB (PDGFBB) involved in oral wound healing stimulates epithelial proliferation and angiogenesis within the injured tissue.Proliferation of epithelial cells in wound healing and formation of new blood vessels (angiogenesis) plays a significant role in healing of keratinized mucosa such as the palate and gingiva. Therefore, TGF- $\beta$ and PDGF, being one of the major growth factors in oral wound healing is found to play a pivotal role in tissue healing of the palatal mucosa after an injury.
\end{abstract}

Keywords-Transforming Growth Factor Beta-1 (TGFB1), Platelet-Derived Growth Factor-BB (PDGF-BB), wound healing, palate

\section{INTRODUCTION}

The process of wound healing is complex as it involves the interaction of many different cells and chemical mediators. This complex process is divided into a few phases; the inflammatory phase, proliferative phase and tissue remodelling phase [1]. At the point of an injury, inflammatory cells and thrombocytes from the bloodstream rushes to the site of injury. Thrombocytes possess a vital role in haemostasis by degranulating and releasing a myriad of growth factors such as platelet-derived growth factor (PDGF) and transforming growth factor beta (TGF- $\beta$ ). From the various types of growth factors found in the injured tissue, PDGF-BB and TGF- $\beta 1$ is able to stimulate proliferation of keratinocytes and fibroblast as well as inducing wound contraction and angiogenesis in oral wounds. Almost all wounds formed in the oral mucosa including the human and pig palate, the healing rate is found to be faster compared to the skin [2].

\section{LITERATURE REVIEW}

A. Phases of wound healing

The normal response in humans and other mammalian species after an injury or loss of skin integrity occurs in three overlapping phases that difference biologically [3]. The formation of fibrin clot is important during the initiation of the wound healing process. During blood coagulation, fibrin was crosslinks with plasma fibronectin to form a clog that ensures haemostasis [2]. After the occurrence of an injury, early inflammatory phase is initiated with the aim of removing non-vital tissues and preventing invasive microbial infections. In the proliferative phase, a balance between formation of scar and tissue regeneration takes place. Under normal circumstances, scar formation often occurs after an injury, but specific 
conditions such as fetal wound healingis capable of complete tissue regeneration. Lastly, the longest and least understood phase of wound healing is remodeling phase, which functions to increase the integrity and endurance of the injured tissue (Figure 1) [3].

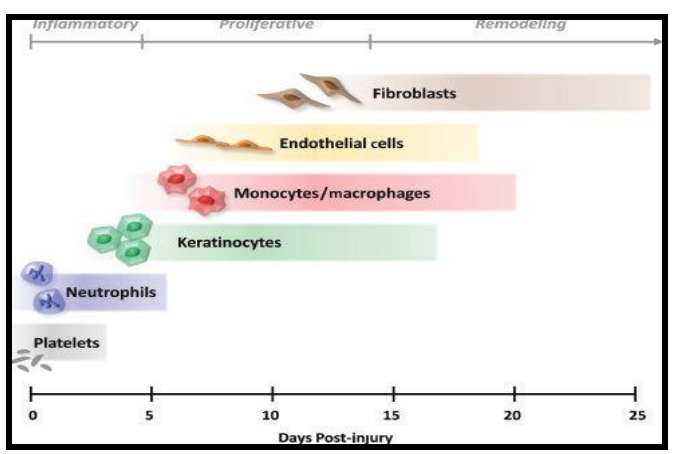

Figure 1. The three phases of wound healing (inflammation, proliferation and remodeling), time taken for each phase in adult cutaneous wound healing and types of cells found in each time period [3]

\section{B. Inflammatory phase}

This phase occurs during the initiation of tissue injury, under conditions whereby factors that prolong inflammation are not present, around 3 to 5 days. Immediately after an injury, the naturally acquired immune cells in the injured tissue stimulate an inflammatory response. There are a few types of natural immune cells on the skin, such as mast cells, dendrite cells, macrophages and a group of specific gamma-delta T-cells. The immune response initiated acts on the injured tissue rapidly with cells like keratinocytes and macrophages capable of producing large amounts of inflammatory mediators within an hour [2].

The purpose of the inflammatory phase is to induce hemostasis, debridement of necrotic tissues and prevention of microbial invasion and colonization [3]. The inflammatory phase is divided into 2 overlapping stages; (1) vascular and (2) cellular. The vascular stage begins when inflammatory response occurs with early vasoconstriction of blood vessels that inhibit flow of blood to the site of injury and subsequently, stimulate blood coagulation. Within minutes, extracellular fluid accumulates to form an edema caused by the migration of histamines, prostaglandin $\mathrm{E}_{1}$ and $\mathrm{E}_{2}$, and leukocytes into the interstitial tissue. At the same time, platelets undergo degranulation and release a few growth factors such as PDGF and TGF- $\beta$ [4].

The early inflammatory phase is noted with neutrophil infiltration mediated by chemotactic agents, such as natural immune cells released by platelets. The main function of neutrophils is to prevent infections by destroying microbial pathogens. Neutrophils consume and metabolize bacteria, foreign substances and defective cells in the injured tissue via phagocytosis. Under normal circumstances, after neutrophil infiltration, the population of macrophages increases in number. Macrophage can be found in two forms, phenotype M1 which is a pro-inflammatory cell that produces pro-inflammatory cytokines and phenotype
M2 which is an anti- inflammatory cell that supports proliferation by promoting the production of growth factors (GF) [2].

Macrophages produce GF that in turn, stimulates angiogenesis and fibrogenesis. Macrophage is capable of inducing apoptosis of neutrophils in vitro. One of the significant functions of the macrophage in wound healing is its ability to inhibit inflammatory response by eliminating neutrophils. Macrophages also have a role in wound healing by activating vital growth factors that increases cell proliferation and protein synthesis. GF is important in wound healing, including TGF- $\alpha$, TGF$\beta$ andPDGF which is secreted by macrophages. The balance between neutrophils and macrophages is extremely important in the wound healing process [3].

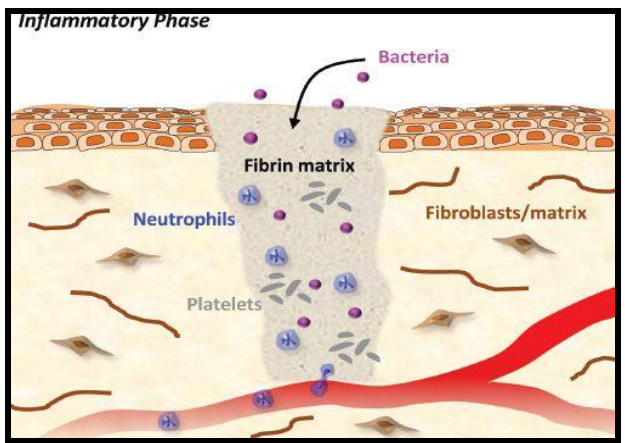

Figure 2. Inflammatory phase of wound healing begins immediately after tissue injury and aims to induce hemostasis, debridement of necrotic tissues and prevention of microbial infections [3].

\section{Fibroblastic/proliferative phase}

Fibrin fibers formed from blood coagulation creates a scaffold in which fibroblasts are able to form ground substance and tropocollagen. This is the fibroblastic phase of the wound healing process. Ground substance composed of many types of mucopolysaccharides functions to unite the collagen fibers. At this stage, fibroblast cells begin to stimulate local mesenchymal cells to produce tropocollagen on the third or fourth day after tissue injury. Macrophages also continue to produce a large number of growth factors like PDGF and TGF- $\beta 1$ which serves to initiate fibroblast proliferation and migration, extracellular matrix deposition and stimulate endothelial cells to form new blood vessels [4].

Along with the fibroplasia process (formation of fibrin network), as the number of cells increase to a certain threshold, fibrinolysis process will be initiated by plasmin found in the blood vessels to remove the overgrowing fibrin mesh. Although the arrangement of collagen is weak, the strength of the wound will increase rapidly during the fibroblastic phase, around 2 to 3 weeks. If the injured tissue is subjected to stress during early fibroplasia, then fibrous tissue will stretch the injury along the point of injury origin. On the other hand, if the injured tissue is subjected to stress during the end of fibroplasia, then the tissue will open along the intersection where old tissue collagen and newly formed collagen are formed (Figure 3) [4]. 


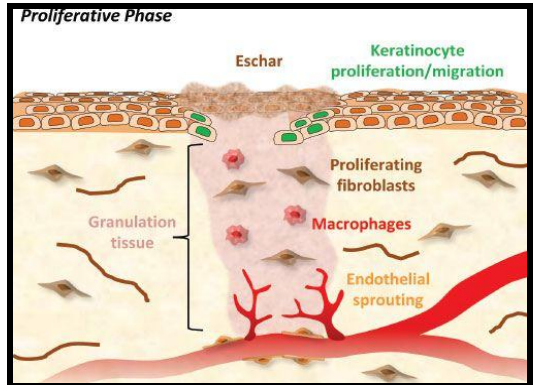

Figure 3. Proliferation phase during the wound healing process begins from day 4 to day 21 post-injury. During this phase, granulation tissue fills the injured site and keratinocytes migrate to the injured site to increase epithelial integrity [3].

\section{Remodeling phase}

The final phase of the wound healing process, which takes place in a sequence, is known as the remodeling phase, however some studies uses the term wound maturation. Throughout this phase, many randomly generated collagenous tissues formed during the fibroblastic phase are destroyed and replaced with newly arranged collagen tissues to withstand the stress forces in the wound. In addition, wound endurance also increases gradually but not with the same strength or rate of proliferation as in the fibroblastic phase. The wound endurance will not exceed $80 \%$ to $85 \%$ of healthy uninjured tissue. Although the pattern of collagen tissue arrangement is more efficient, only a small portion of tissue will be left while most of the tissue will be removed until the scar formed becomes softer. With reduced cell metabolism in the wound, vascularity will decrease along with erythema. Elastin found in the skin and ligaments will not be replaced during the wound healing process. Due to this, injury to the tissue will result in a loss of flexibility in the scarred area (Figure 4) [4].

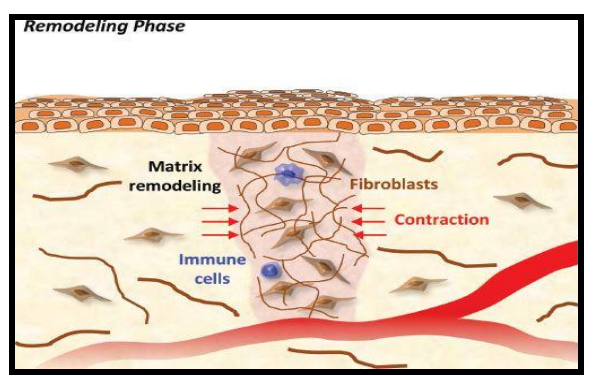

Figure 4. Remodeling phase of wound healing is the longest phase that occurs from day 21 to 1 year, post-injury. Although it is not fully understood, the remodeling phase involves wound contraction and collagen remodeling [3].

The final process that begins at the end of fibroplasia and continuous during the initial phase of remodelling is wound contraction. In most cases, wound contraction plays an important role in wound healing even though the mechanism of the process remains unclear. During wound contraction, the ends of the wound migrate towards each other thus reducing the size and severity of the wound. An example of abnormal wound contraction is found in individuals with sharp lacerations, whereby some tissue is formed around the scar due to contraction of the wound although the ends of the woundhad already adapted. Wound contractions can be reduced by placing a thin layer of epithelium between the free ends of the wound. The surgeon uses this technique when placing a skin graft on the periosteum during vestibuloplasty surgery or in cases of deep burn [4].

\section{E. Platelet-derived growth factor- $B B$}

Around mid-1970s, some researcher's had found a type of growth factor secreted by platelets, capable of stimulating fibroblast and smooth muscle cells. These growth factors were collectively known as plateletderived growth factors (PDGF) and were later purified after several years by Heldin, et al. PDGF is a $30 \mathrm{kDa}$ dimer consisting of chain A and / or chain B, encoded by different genes and functions. Recently, two additional genes had been found that encode the PDGF$\mathrm{C}$ and PDGF-D polypeptides. To date, five dimeric compositions had been identified as PDGF-AA, -BB, $\mathrm{AB}$, -CC and -DD [5]. The PDGF's target of action includes mesoderm derived cells such as fibroblasts, pericytes, smooth muscle cells, glial cells and mesangial cells $[5,6]$. Isoform PDGF binds to two different types of class III tyrosine kinase receptors PDGFR $\alpha$ and PDGFR $\beta$. PDGFR $\alpha$ has a high affinity with PDGF-A, $B$ and $-C$, while PDGFR $\beta$ is highly affluent with PDGF$B$ and-D [5].

TABLE I. GROWTH FACTORS INVOLVED IN THE WOUND HEALING PROCESS [2,3]

\begin{tabular}{|c|c|c|}
\hline Growth Factor & Source & Function \\
\hline $\begin{array}{l}\text { EGF (epidermal growth } \\
\text { factor) }\end{array}$ & $\begin{array}{l}\text { Platelets, macro-phage, } \\
\text { fibroblast, plasma, } \\
\text { saliva }\end{array}$ & $\begin{array}{l}\text { Stimulate collagenase secretion by } \\
\text { fibroblast for matrix remodelling }\end{array}$ \\
\hline $\begin{array}{l}\text { FGF-2 (basic fibroblast } \\
\text { growth factor or FGF) }\end{array}$ & $\begin{array}{l}\text { Macrophage, mast } \\
\text { cells, endothelial cell, } \\
\text { T-lymphocyte, } \\
\text { keratinocyte, fibroblast }\end{array}$ & $\begin{array}{l}\text { Stimulates angiogenesis and } \\
\text { initiates angiogenesis. } \\
\text { - Stimulates epithelization through } \\
\text { migration and proliferation of } \\
\text { keratinocytes and fibroblast as } \\
\text { well as collagenase synthesis }\end{array}$ \\
\hline $\begin{array}{l}\text { IGF-1 (insulin like } \\
\text { growth factor-1) }\end{array}$ & $\begin{array}{l}\text { Plasma, platelet, } \\
\text { keratinocyte, } \\
\text { endothelial cell, } \\
\text { fibroblast, }\end{array}$ & $\begin{array}{l}\text { Stimulates proliferation of fibroblast } \\
\text { and extracellular matrix deposition }\end{array}$ \\
\hline $\begin{array}{l}\text { NGF (nerve growth } \\
\text { factor) }\end{array}$ & $\begin{array}{l}\text { Mast cell, eosinophil, } \\
\text { keratinocyte, fibroblast }\end{array}$ & $\begin{array}{l}\text { Stimulates migration of fibroblast, } \\
\text { differentiation of myofibroblast and } \\
\text { collagen contraction }\end{array}$ \\
\hline $\begin{array}{l}\text { PDGF (platelet derived } \\
\text { growth factor) }\end{array}$ & $\begin{array}{l}\text { Platelet, macrophage, } \\
\text { endothelial cell, } \\
\text { fibroblast, keratinocyte }\end{array}$ & $\begin{array}{l}\text { - Stimulates proteoglycan and } \\
\text { collagen synthesis } \\
\text { - Activates macrophage and } \\
\text { fibroblast }\end{array}$ \\
\hline $\begin{array}{l}\text { TGF- } \alpha \text { (transforming } \\
\text { growth factor- } \alpha \text { ) }\end{array}$ & $\begin{array}{l}\text { Platelet, macrophage, } \\
\text { keratinocyte and } \\
\text { eosinophil }\end{array}$ & Stimulates fibroblast proliferation \\
\hline $\begin{array}{l}\text { TGF- } \beta 1, \beta 2 \text { and } \beta 3 \\
\text { (transforming growth } \\
\text { factor- } \beta \text { ) }\end{array}$ & $\begin{array}{l}\text { Platelet, macrophage, B } \\
\text { and T cell, hepatocyte, } \\
\text { thymocytes, placenta }\end{array}$ & $\begin{array}{l}\text { - Stimulates angiogenesis } \\
\text { - Stimulates activation of } \\
\text { proinflammatory molecules that } \\
\text { causes migration of leukocytes } \\
\text { and fibroblast } \\
\text { - Stimulates extracellular matrix } \\
\text { synthesis by inhibiting protease } \\
\text { activity and increase } \\
\text { proteoglycan-can and collagen } \\
\text { synthesis }\end{array}$ \\
\hline $\begin{array}{l}\text { VEGF (Vascular } \\
\text { endothelial growth } \\
\text { factor) }\end{array}$ & Endothelial cell & Stimulates angiogenesis \\
\hline $\begin{array}{l}\text { KGF (Keratinocyte } \\
\text { growth factor) }\end{array}$ & \begin{tabular}{|l} 
Fibroblast \\
\end{tabular} & $\begin{array}{l}\text { - Controls growth and maturation } \\
\text { of keratinocytes } \\
\text { - Stimulates secretion of secondary } \\
\text { growth factors }\end{array}$ \\
\hline $\begin{array}{l}\text { (G-CSF) Granulocyte } \\
\text { colony-stimulating } \\
\text { factor }\end{array}$ & $\begin{array}{l}\text { Stromal cell, fibroblast, } \\
\text { endothelial cell, } \\
\text { lymphocyte }\end{array}$ & $\begin{array}{l}\text { Stimulates proliferation, } \\
\text { maturation and activation of } \\
\text { granulocytes } \\
\text { - Induce granulopoiesis }\end{array}$ \\
\hline $\begin{array}{l}\text { GM-CSF (Granulocyte- } \\
\text { macrophage colony- } \\
\text { stimulating factor) }\end{array}$ & $\begin{array}{l}\text { Macrophage, stromal } \\
\text { cell, fibroblast, } \\
\text { endothelial cell, } \\
\text { lymphocyte } \\
\end{array}$ & $\begin{array}{l}\text { Stimulates proliferation, } \\
\text { maturation and activation of } \\
\text { granulocytes and macrophages } \\
\text { - Induce granulopoiesis }\end{array}$ \\
\hline
\end{tabular}


Study by Heldin \& Westermark found that PDGFBB homodimer was produced by cells with PDGF-B expression and the results showed that the PDGF family consisted of 3 types of proteins namely PDGF-AA, PDGF-AB and PDGF-BB encoded by two types of genes, PDGF -A and PDGF B. However, after 15 years, it turns out that there were two more types of genes and additional proteins, namely, PDGF-C and PDGF-D. Although endogenous protease enzymes that functions in PDGF-B activation had not been identified, recent studies had discovered role of thrombin as a potential substance in stimulating extracellular proteolysis. With that, cells with PDGF-B expression will secrete soluble PDGF-BB into the extracellular medium [7].

PDGF is stored in platelets and produced by macrophages, which possesses the function of increasing the number of mesenchymal cells in the wound. This may occur through two activities: (1) in the presence of platelet build-up in the wound, the platelets will release PDGF which will then seep into the surrounding tissue and act as a chemoattractant to mobilize cells to the wound area; (2) in large amounts within the wound, PDGF increases cell proliferation. In this way, PDGF can regulate the number of cells in the wound tissue and stimulate deposition of extracellular matrix [7]. PDGF is capable of activating TGF- $\beta$; stimulate neutrophils, fibroblasts and smooth muscle cells, collagen synthesis and activation of collagen [6].

The specific function of PDGF is to stimulate mitogenesis (an increase in cell population for wound healing), angiogenesis (mitosis of endothelial cells within functional capillaries) and macrophage activation (wound debridement and triggers secondary growth factors for tissue repair and bone regeneration) (Figure 5) $[8]$.

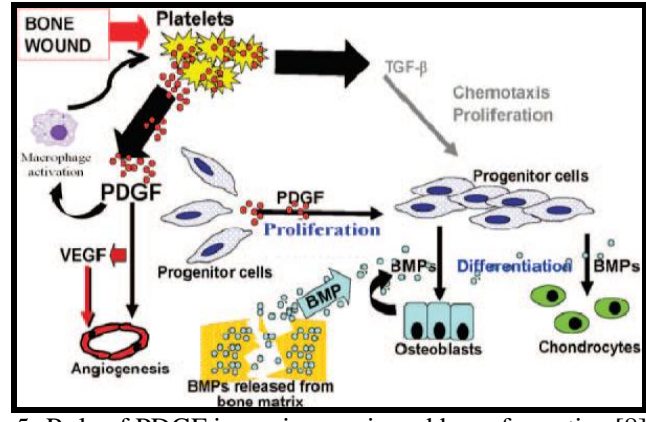

Figure 5. Role of PDGF in angiogenesis and bone formation [8].

\section{F. Wound healing by PDGF}

Soft tissue healing involves the process of reepithelization, angiogenesis and deposition of the extracellular matrix. There are three research studies that support the influence of PDGF in wound healing namely, the effect of PDGF in vitro on essential cells in healing, PDGF expression analysis and PDGF receptors during wound healing and research on the effects of topical PDGF applications on wound healing [8].

PDGF stimulates mitosis and chemotaxis of fibroblasts and smooth muscle cells, as well as chemotaxis of neutrophils and macrophages. These growth factors also stimulate macrophages to produce and secrete other growth factors with specific functions during the wound healing phases. PDGF is also found to be able to stimulate the synthesis of matrix molecules such as fibronectin, collagen, proteoglycans and hyaluronic acid. At the end of the wound healing phase, PDGF may play a role in stimulating the contraction of the collagen matrix in vitrothat may have the same effect in vivo. In addition, during the remodeling phase, PDGF stimulates the production and secretion of collagenase by fibroblasts. In order for PDGF to affect wound healing in vivo, these growth factors should be present in the wound area. Some studies have found that PDGF is released by platelets and secreted by active macrophages, endothelial cells stimulated by thrombin, smooth muscle cells from damaged arteries, active fibroblasts and epidermal keratinocytes. At the same time, with more use of specific monoclonal antibodies, more PDGF-AA was found in capillaries and fibroblast cells in acute wounds and PDGF-BB were found in chronic wounds; while no PDGFs were found in healthy skin and non-healing skin ulcers [8].

PDGF-BB application on incision wounds was found to increase wound tissue resistance by $150 \%$ $170 \%$ compared to wound without PDGF-BB application and was able to reduce the healing time of tissues. Wounds treated with PDGF shows an increase in granulation tissue rich with fibroblasts, glycosaminoglycan and an increase in reepithelialization and tissue neurovascularization. Thus, it can be concluded that PDGF does not change the process of tissue repair but accelerates its healing. PDGF-BB can also increase the rate of healing in patients with healing abnormalities such as diabetes [8].

\section{G. Transforming growth factor- $\beta 1$}

The TGF- $\beta$ superfamily consists of 33 members, most of which are polypeptides secreted by cells. In addition to the three isoform prototypes of TGF- $\beta$ (TGF- $\beta 1$, TGF- $\beta 2$ and TGF- $\beta 3$ ), this superfamily also involves activin, inhibin, Bone Morphogenetic Proteins (BMPs), Growth and Differentiation Factors (GDFs), miostatin, nodal, leftis and Mullerian Inhibiting Substance (MIS) [9].

TGF- $\beta$ is attracted to fibroblasts, keratinocytes and inflammatory cells via chemotaxis. ${ }^{2}$ In the majority of tissues in the body, there is a certain amount of TGF- $\beta$ stored in the extracellular matrix. Activation of TGF- $\beta$ is stimulated by protease-breaking activities including elastase and metalloprotease matrixes (MMPs) or through integrin-induced changes. TGF- $\beta$ has several known important functions in the wound healing process. The function of TGF- $\beta$ is to regulate the proliferation, differentiation, migration, invasion and chemotaxis of epithelial cells, fibroblasts and immune cells (inflammatory phase) of tissue, as well as the proliferation, migration, invasion and maturation of endothelial cells (to produce functional blood vessels) during angiogenesis $[1,2,9]$. 
Immediately after an injury, TGF- $\beta$ is released by platelets and secreted as chemoattractant for parenchymal cells and leukocytes that increases the production of TGF- $\beta$. TGF- $\beta$ stimulates the formation of extracellular matrix (ECM) by fibroblasts and prevents ECM degradation. This mechanism leads to tissue formation in normal wound recovery [1].

\section{- Inflammation/hemostasis phase}

TGF- $\beta$ isoform shows dynamic interactions during haemostasis and inflammatory processes. After an injury, blood vessels will be damaged and this will bring platelets to sub-endothelial collagen which will lead to platelet accumulation and degranulation, hence activating blood coagulation cascade. Alpha granules in platelets are rich in TGF- $\beta 1$ (40-100 times more than other cells). Alpha granules also contain other TGF- $\beta$ isoforms, but the number of isoforms is much lower compared to TGF- $\beta 1$ (4000 TGF- $\beta 1$ : 1 TGF- $\beta 2$ : 10 TGF- $\beta 3$ ). Activation of the blood coagulation mechanism by platelets will cause fibrin clumping resulting in haemostasis and formation of ascaffold for inflammatory cell migration to the injured tissue [9]. After haemostasis, TGF- $\beta$ acts as achemo-attractant and an inflammatory mediator for many immune cell types, including neutrophils and other polymer-phonuclear (PMN) cells (24 to 48 hours post injury) and monocyte cells (48 to 96 hours post injury). At the same time, TGF- $\beta$ ligands have the ability to inhibit other chemoattractants for neutrophils such as interleukin-8, and suppress immune cell's ability to transmigrate to the injured tissue. Thus, TGF- $\beta$ was found to stimulate both initial immune responses, through PMN mobilization and limit the inflammatory response. Although platelets are said to be very rich in TGF- $\beta 1$, but in neutrophils, the ratio of TGF- $\beta$ isoforms is very different from that of platelets with more TGF- $\beta 3$ (12 TGF- $\beta 1$ : 1 TGF- $\beta 2$ : 34 TGF- $\beta 3$ ), indicating that there is a specific difference in TGF- $\beta$ isoform throughout the wound healing process. In addition, the role of macrophages in triggering formation of granulation and angiogenesis tissue is also stimulated by TGF- $\beta$ [9].

\section{- Proliferative phase}

Proliferative phase involves three main activities triggered by TGF- $\beta$ : re-epithelization, angiogenesis and synthesis of extracellular matrix. Prior to injury, TGF$\beta 1$ in the epidermis acts as a homeostatic cytokine, inhibiting the development of the cell cycle process and suppresses epithelial hyperplasia. After an injury, the three TGF- $\beta$ isoforms trigger re-epithelialization and destruction of TGF- $\beta$ (via the antibody neutralization effect) that disrupts wound closure. However, although TGF- $\beta 1$ plays a role in stimulating keratinocyte migration, TGF- $\beta 3$ has no such function [9].

The angiogenesis process involves invasion of the wound cells that will form micro vascular tissue. Although it is not fully understood, the role of TGF- $\beta$ as an intermediary in angiogenesis had long been recognized by many researchers. The ability of TGF- $\beta$ to trigger angiogenesis may be related to its ability to stimulate exposure of vascular endothelial growth factor (VEGF) in the injured site. VEGF regulates angiogenic activity during the wound healing proliferation phase and TGF- $\beta$ is able tomobilize hematopoietic- effector cells - VEGF to stimulate angiogenesis. Finally, TGF- $\beta$ is involved in the synthesis of extracellular matrix and fibroblast cell deposition from the surrounding dermal layer and bone marrow (fibrocyte). After entering the injured tissue, fibroblasts will proliferate and begin forming a temporary extracellular matrix (consisting of collagen and fibronectin) before forming an intact granulation tissue. TGF- $\beta 1$ regulates the formation of collagenous fibroblasts (especially types I and III), and also inhibits MMP. Although TGF- $\beta 1$ and TGF- $\beta 2$ stimulate collagen deposition and scar tissue formation, TGF- $\beta 3$ is found to be antifibrotic. Thus, the combined effects of TGF- $\beta 3$ and TGF- $\beta 1$ can regulate and offset the process of collagen formation. At the end of the proliferative phase, some fibroblast cells will undergo differentiation to form myofibroblasts while others will undergo apoptosis, hence initiating the finalphase of wound healing, the remodeling phase [9].

\section{- Remodeling phase}

The final phase of wound healing which is the remodelling phase involves apoptosis of the resident cells (including fibroblasts and endothelial cells) and wound contraction as well as the replacement of fibronectin and collagen type III with collagen type I. As a result, granulation tissue rich with cells and vascularization will turn into a scar which is avascular and acellular. Similar to TGF- $\beta 1$, TGF- $\beta 2$ also acts as a trigger for fibroblast transition to myofibroblasts. However, the role of TGF- $\beta 3$ is more complex. In vitro, TGF- $\beta 3$ was found to be capable of triggering the formation of myofibroblasts but in vivo, TGF- $\beta 3$ inhibited the formation (Fig. 6) [9].

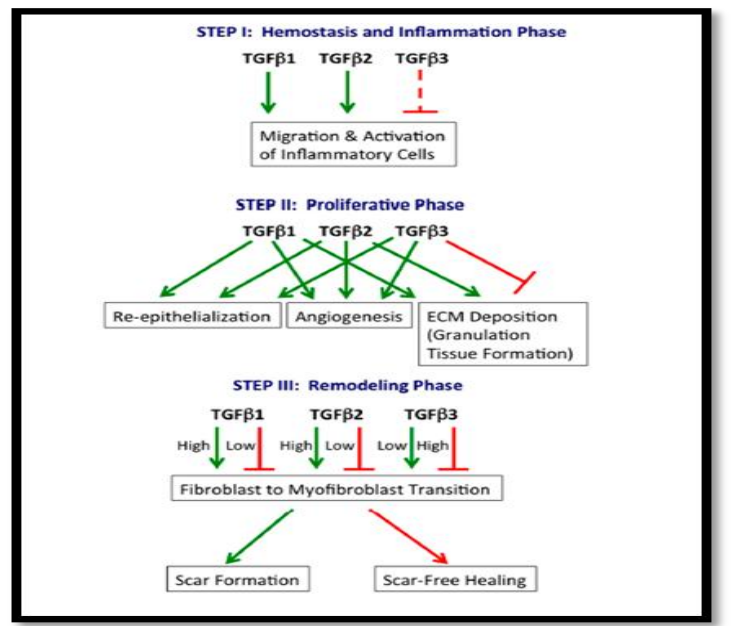

Figure 6. Isoforms of TGF- $\beta$ in wound healing. TGF- $\beta 1$, TGF- $\beta 2$ and TGF- $\beta 3$ work together in the three phases of wound healing. In general, TGF- $\beta 1$ and TGF- $\beta 2$ are triggers, while TGF- $\beta 3$ is an inhibitor. However, TGF- $\beta 3$ can also stimulate certain processes (e.g. reepithelization). Green arrow: trigger effect; A continuous red line: an inhibitor; Dotted red line: potential inhibitor [9]. 


\section{H. Platelet-derived products}

Marx et al. demonstrated a potential use of Platelet Rich Plasma (PRP) in craniofacial bone grafts in the late nineties and since then, plasmatic fractions had been utilized as a suitable source of growth factors. PRP is defined as a component of plasma fraction of venous blood with platelet counts in the range between 4 and 6 times above baselines ( 1 million platelets/L). The preparation of PRP by centrifugation was initially conductedusing a "two-step gradient centrifugation method." A strong first spin was used first in order to separate the erythrocytes from the clotting factors, platelets, and leukocytes. Then, the plasma was subjected to a second centrifugation step, to harvest the PRP fraction from the platelets and leukocytes. Finally, platelets in PRP were activated to release the biomolecules, using thrombin or calcium chloride. Other authors had proposed alternative methods to release growth factors fromplatelets, such as lysing the platelets by freezing them or using sonication or ultrasound activation. Once the release of biomolecules from platelets is activated, a network is formed to establish a fibrin clot that acts as scaffold for growth factors over a limited period of time. Nowadays most of the commercially accessible kits involve a one-step method to separate the plasma into three distinct layers: the erythrocytes, the buffy coat containing PRP, and the Platelet Poor Plasma (PPP). Currently, plasmatic fractions have been classified according to at least two key parameters: the presence of leukocytes and the fibrin architecture. Following these criteria, we can find four family fractions (Figure 7) [10].

\section{Pure Platelet-Rich Plasma (P-PRP) low or} without leukocytes

Plasmatic preparations from anticoagulated venous blood "without leukocytes and with a low-density fibrin network." Leukocyte count of these samples is lower than the whole blood percentage. After its activation with calcium chloride or thrombin, this preparation can be used as a liquid solution or as a gel [10].

\section{Platelet-rich Plasma (L-PRP) with leukocytes}

Plasmatic fractions from anticoagulated venous blood "with leukocytes and with a low-density fibrin network." The leukocytes content in these preparations is at least five times compared with the base line of whole blood count. Following activation, L-PRP might be used either as a liquid solution or in an activated gel form. Among the commercial systems available are Harvest Smart- PreP (Harvest Technologies, Plymouth, MA, USA), Biomet GPS III (Biomet Inc., Warsaw, IN, USA), Plateltex (Prague, Czech Republic), and Regen PRP (RegenLab, Le Mont-sur-Lausanne, Switzerland) [10].

\section{Pure Platelet-rich Fibrin (P-PRF) low or} without leukocytes

These correspond to "preparations without leukocytes and with a high-density fibrin network."
Fibrin, in combination with growth factors, has been shown to effectively support cell adhesion and proliferation. P-PRF only exists in a solid activated gel form. To date, only one product of this family is commercially available, known as Fibrinet PRFM (Platelet- Rich Fibrin Matrix, Cascade Medical, Wayne, NJ, USA) [10].

\section{Platelet-rich Fibrin (L-PRF) with leukocytes}

Also named Choukroun's PRF. In this preparation, venous blood is obtained without any anticoagulant and directly centrifuged. A cascade of calcium chloride or thrombin is used, which results in the isolation of this plasmatic fraction without any biochemical modifications. These preparations, existing only in gel form, have leukocytes and a high-density fibrin network [10].

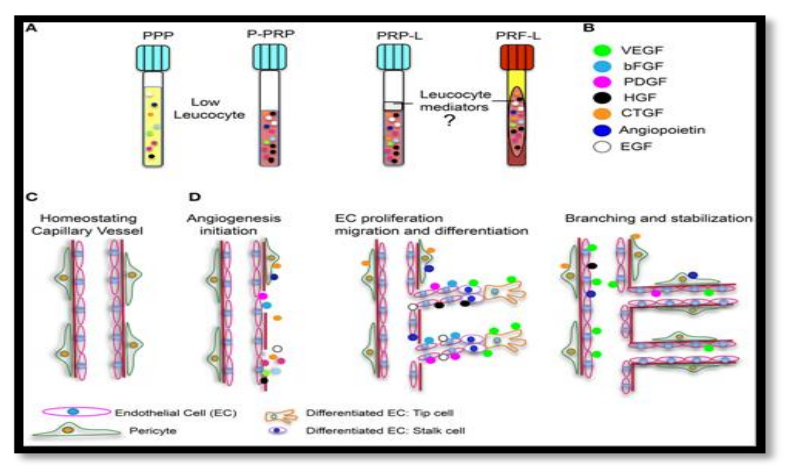

Figure 7. Platelet derived fractions and involvement in angiogenesis. (A) Four platelet-derived fractions are illustrated. Two with low leukocyte content (PPP and P-PRP) and two with high leukocyte content (L-PRP and L-PRF). (B) Angiogenic growth factors are represented with the indicated color code. (C) Illustration of a capillary blood vessel in physiological conditions. (D) Influence of angiogenic growth factors during angiogenesis initiation, endothelial cell proliferation and branching of new blood vessels.

Hence, as a rich source of growth factors, plateletrich plasma (PRP) is used in tissue engineering to increase the levels of growth factors by releasing them from intracellular stores. A myriad of growth factors can be found in PRP; these include platelet-derived growth factor (PDGF) and transforming growth factor (TGF)- $\beta 1$; both of which are involved in regulation of bone regeneration. Due to PRP being an autologous product, it also eliminates concerns about immunogenic reactions and disease transmission between individuals [11]. Platelet concentrate (PC) is an enhanced concentration of platelets processed from PRP $[10,12]$. A few studies reported that PC and PRP contain five to seven times the concentration of platelets of normal blood. These studies indicate that PC affects cell biologic activities that can increase the rate of tissue healing and maturation by exerting a positive influence on mitogenesis, angiogenesis and promotion of cellular differentiation at the wound site [12].

\section{Effect of PDGF-BB and TGF- $\beta 1$ in palatal healing}

In a study conducted by Yen AC, et al. in 2007, 20 adult patients with bilateral gingival recessions were 
treated with connective tissue graft (CTG) and platelet concentrate gel (PC) in combination with CTG. The donor area (palate) was treated with $\mathrm{PC}$ and placebo. All patients were re-controlled after 1, 2, 4 and 6 weeks postoperatively. Biopsy was carried out by taking tissue samples from the donor region for histological examination and immuno-histochemical analysis of collagen types I and III. The thickness of the palatal tissue, postoperative complications and the level of pain were also evaluated in this study. The results show that the palatal donor areas treated with PCs experienced $1.10 \mathrm{~mm}$ thickening of tissue compared to the palatal donor area treated with placebo (Figure 8) [12].

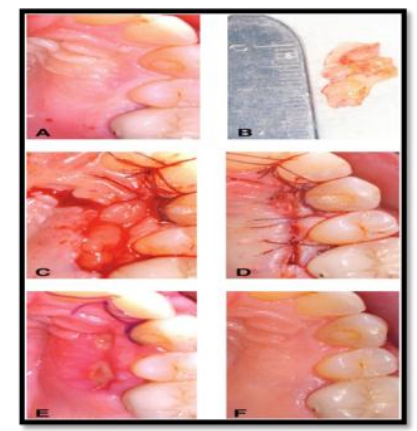

Figure 8. Clinical procedures for taking CTG (graft) and care of palatal donors with PC gel. A) Clinical features of donor areas. B) Graft taken. C) PC gel was applied to the donor area. D) The donor area is sewn to cover the wound. E) Healing after 1 week post-surgery. F) Healing after 6 weeks post-surgery [12].

In addition, PC-treated tissue graft receptors experience faster clinical healing than controls. However, the PC was found unable to speed up the healing process in the donor region. The biopsy sample showed that during the healing process, the area treated with PC gel had a slight inflammatory cell content, more mature type I collagen and less collagen type III than the control site [12].

This study shows that TGF- $\beta$ plays an important role in stimulating the growth and development of palatal epithelium and connective tissue. Therefore, the increase in the number of growth factors can increase the income of fibroblast cells and myofibroblasts, thus stimulating cell growth and proliferation faster than normal healing. PDGF also stimulates the formation of transient cellular matrix after the re-epithelization process. Research by Garg, et al. states that all platelets present in rich plasma platelets (PRPs) will undergo degranulation within 3 to 5 days enablinga large amount of growth factors to stimulate rapid healing [12].

\section{DISCUSSION}

The formation of scar tissue depends on the location and extent of the wound. Oral lesions show less inflammation than skin lesions, with fewer neutrophils, macrophages and T-cell infiltrates. Reduced levels of TGF- $\beta 1$ are associated with minimal formation of scar tissue in the oral mucosa. The change in levels of TGF$\beta 1$ and $-\beta 3$ holds an important key in healing of the oral mucosa [2].
TGF- $\beta 1$ mRNA and protein levels were significantly reduced in wound of oral origin than in skin lesions. The initial wound on the gingiva has a higher protein content and TGF- $\beta 1$ than the antifibrotic TGF- $\beta 3$ isoform, and this GF persists for a longer time. TGF- $\beta 1$ reduces the proliferation of oral fibroblasts but increases growth of dermal fibroblasts [1]. PDGF appears to trigger the release of hyaluronan and certain proteoglycans and reduces the differentiation of myofibroblasts [1,2].

Wound inflammation in the oral mucosa occursless frequently than the skin. Reduced inflammation can accelerate the process of repair, cellular proliferation and cell migration.[2] TGF- $\beta 1$ is closely linked to the differentiation of myofibroblast, increased matrix accumulation, enhanced inflammatory cellular chemotaxis, and also increased hypertrophic scarring and scar tissue formation [1,2].

PDGF plays a significant role in wound healing and tissue formation by stimulating proliferation of fibroblasts, smooth muscle arterial cells, chondrocytes and epithelial and endothelial cells, acts as a chemoattractant for hematopoietic cells and mesenchymal cells, fibroblasts and muscle cells and activates TGF- $\beta$ which in turn, stimulates neutrophils and macrophages, mitosis of fibroblasts and smooth muscle cells, collagen synthesis, activation of collagen, and angiogenesis $[6,8]$.

\section{REFERENCES}

[1] J.E. Glim, M.V. Egmond, F.B. Niessen, V. Everts, R.H.J Beelen, "Detrimental dermal wound healing: What can we learn from the oral mucosa?" Wound Healing Soc., vol. 201, pp. 1-9.

[2] H. Larjava, Oral wound healing, cell biology and clinical management, UK: John Wiley \& Sons, Inc., 2012, pp. 24-26, 39-50, 125-126, 149-150.

[3] C.H. Thorne, Grabb and Smith's plastic surgery, $7^{\text {th }}$ ed. Philadelphia: Lippincott Williams \& Wilkins, 2014, pp. 15-22.

[4] J.R. Hupp, E. Ellis, M.R. Tucker, Contemporary oral and maxillofacial surgery, $6^{\text {th }}$ ed., St. Louis: Elsevier Mosby, 2014, pp. 44-46.

[5] M. Raica, A.M. Cimpean, "Platelet-derived growth factor (PDGF)/PDGF receptors (PDGFR) axis as target for antitumor and antiangiogenic therapy," J. Pharmaceuticals vol. 3, pp. 572599, 2010.

[6] P. Rozman, Z. Bolta, "Use of platelet growth factors in treating wounds and soft-tisue injuries," Acta Dermatoven APA, vol. 16, pp. 156-165, 2016.

[7] J. Andrae, R. Gallini, C. Betsholtz, "Role of platelet-derived growth factors in physiology and medicine," J. Genes Dev., vol. 22, pp. 1276-1312, 2008

[8] P. Shah, L. Keppler, J. Rutkowski. "A review of platelet derived growth factor playing pivotal role in bone regeneration," $\mathrm{J}$. Implantol., vol. 40(3), pp. 330-340, 2014.

[9] R.W.D. Gilbert, M.K. Vickaryous, A.M. Viloria-Petit, "Signaling by transforming growth factor beta isoforms in wound healing and tissue regeneration," J. Dev. Biol., vol. 4(21), pp. 1-21, 2016

[10] C.E. Martinez, P.C. Smith, A. Veronica, P. Alvarado, "The influence of platelet-derived products on angiogenesis and tissue repair: A concise update," Front Physiol., vol. 6, pp. 1-7, 2015.

[11] H. El-Sharkawy, A. Kantarci, J. Deady, et al., "Platelet-rich plasma: Growth factors and Pro- and Anti-Inflammatory Properties,” J. Periodontol., vol. 78(4), pp. 661-669, 2007.

[12] C.A. Yen, T.J. Griffin, W.S. Cheung, J. Chen, "Effects of platelet concentrate on palatal wound healing after connective tissue graft harvesting," J. Periodontol., vol. 78(4), pp. 601-610, 2007. 